Article

\title{
Peer relationships at residential care institutions for unaccompanied refugee minors: an under-utilised resource?
}

\section{Guro B Omland}

University of Oslo, Norway; Norwegian Centre for Violence and Traumatic Stress Studies, Oslo, Norway

\section{Agnes Andenas}

University of Oslo, Norway

\begin{abstract}
Without access to their own families, how do young, unaccompanied refugee minors reestablish their social lives in ways that facilitate a sense of togetherness in their everyday lives during resettlement? This question was approached by exploring the young persons' creation of relational practices and the kinds of sociomaterial conditions that seemed to facilitate the evolvement of these practices, including the professional caregivers' contributions. Interviews with 11 boys and 4 girls (aged 13-16) from Afghanistan, Somalia, Angola and Sri Lanka, as well as their professional caregivers in their country of residence, Norway, were analysed systematically by searching for, and categorizing, the variation of relational practices among the young persons. Three overarching practices are presented. First, the young persons worked to connect past, present and future contexts through collective meaning-making practices. Second, they regulated their peers' emotions through emotional care practices. Third, they widened each other's social networks through practices of social inclusion. Following the resettlement procedure the young persons moved from one kind of institution (care centres) to other parts of the country and to another kind of institution (group homes) where the relational practices mentioned above appeared to be less prevalent. The article suggests that arranging everyday life as collective enterprises, as well as housing peers with similar cultural backgrounds, were central for the evolvement of the relational practices. As such, the article both elucidates a range of health-promoting relational practices that the young persons' realised as a group as well as how these practices are embedded in sociomaterial conditions.
\end{abstract}

\section{Keywords}

Unaccompanied refugee minors, cultural psychology, conduct of everyday life, relational practices, social support, peer support, development, health-care work

Corresponding author: Guro Brokke Omland, Department of Psychology, University of Oslo, P.O Box 1094 Blindern N-0317, Oslo, Norway. 


\section{Introduction}

When young people legally considered as unaccompanied asylum-seeking minors arrive in their host country, they do so without the protection and care of their families and wider social networks. They live with losses of loved ones and traumatic experiences from war and conflict (Jensen et al., 2015), find themselves in countries where public debate regularly constructs them as either child victims or strategic migrants (Stretmo, 2014), and they fear a rejection of their asylum application (Sourander, 1998). In this stressful situation, they are faced with the task of fully redeveloping their social networks (Ní Raghallaigh, 2011). Experiences of loneliness and lack of social support are commonplace (Oppedal et al., 2009). Health-related research has documented the health benefits of social support as well as the health risks of its absence, in general (Cohen, 1992), and specifically in the case of unaccompanied minors (Oppedal and Idsoe, 2015). Still, knowledge regarding the ways in which social support contributes to the young persons' health and well-being, and under what conditions such support evolves, remains sparse. This article is based on a study of 15 unaccompanied young people's re-establishment of their social lives in the resettlement phase. We focused on the ways in which the young persons created relational practices that seemed to facilitate a 'sense of togetherness'. For policymakers and professionals seeking to 
facilitate the health and development of resettled young people, these processes are crucial to understand.

\section{The resettlement process in a Norwegian context}

In Norway, the resettlement for unaccompanied refugee minors below 15 years of age at $\operatorname{arrival}^{1}$ can be described as a two-step process. Once the young asylum-seeking minors have arrived in Norway and have been registered at the reception office, they are immediately placed at asylum reception centres. These centres, hereafter called 'care centres' (in Norwegian: 'Omsorgssentre'), are organised by the Child Welfare Services and specifically arranged for unaccompanied asylum-seeking minors below the age of 15. Ideally, the young persons stay here for no more than three months. However, many stay longer due to delays in legal and resettlement proceedings.

Those who are granted a residence permit are resettled in municipalities in different parts of Norway. The youngest move to foster homes, but most are placed in shared accommodation care arrangements, hereafter called 'group homes' (in Norwegian: 'Bofellesskap'), typically with three or four other young, unaccompanied refugee minors. The care centres as well as the group homes are staffed with personnel both day and night.

Theoretical framework and research questions 
Informed by theoretical perspectives from cultural developmental psychology (Haavind, 1987; Rogoff, 2003; Valsiner, 2000), we explored the young people's social lives by focusing on their participation in social practices in everyday life. Participation is embodied and always situated in particular locations (Dreier, 2016). Thus social practices are practically inseparable from the specific settings of everyday life - the meeting place of all activities with their differences and conflicts (Lefebvre, 1991: 97), and 'the space in which our social relations are produced and reproduced' (Schraube and Højholt, 2016: 2). Everyday life is societally arranged, socially grounded and subjectively experienced, and as such represents an analytical site where the environment and subject expand together to form a nexus (Dreier, 2016). The concept 'conduct of everyday life' seeks to capture this nexus by focusing on 'human subjectivity from the standpoint of where and how subjects live their everyday lives in societal structures of practice' (Dreier, 2016: 15). To underline that material conditions restrict and enable particular conducts of everyday life, the concept of 'sociomateriality' (Tanggaard, 2013) is employed.

Because we were interested in 'social support' we explored the practices that seemed to be related to togetherness, implying shared emotional connection, sense of belonging, mutual influence and fulfilment of needs, or 'sense of community' (McMillan and Chavis, 1986) in everyday life. Such experiences are considered as central aspects of mental health (Hagerty et al., 1992). In order to underline the affective 
and experiential aspects of these practices, we preferred the concept 'sense of togetherness', implying that the political and ideological projects that construct belongings in particular ways ('the politics of belonging') (Yuval-Davis, 2006) were in the background. To guide our analytical gaze towards the variety of ways relationships are 'done', the concept 'relational practices', inspired by the concept 'family practices' (Morgan, 2011), was chosen.

The research questions are as follows: How do the young persons create relational practices that facilitate a sense of togetherness during resettlement, and how are these practices grounded in everyday life at the residential care institutions?

\section{Methods}

In order to answer these research questions, exploration of the young persons' descriptions of everyday life was crucial. Moreover, to examine how their everyday life develop and change during resettlement, interviews were conducted both before and after they moved to new municipalities following the resettlement procedure. As will be described, the conduct of everyday life before and after moving differed significantly, as did the evolvement of the relational practices of interest.

\section{Recruitment}


Participants were recruited via several steps. First, ethical approval of the research project was obtained from the National Committee for Medical and Health Research Ethics, and clearance to contact the children was provided by the Norwegian Office for Children, Youth and Family Affairs. All five care centres for unaccompanied asylumseeking children in Norway were contacted, and all agreed to take part. Subsequently, the legal guardians of children who had recently been provided with temporary residence permits were contacted. ${ }^{2}$ With the applicable guardian's consent, the interviewer contacted the young person by telephone and informed him/her about the research project, assisted by an interpreter on the telephone line. The interviewer underlined that participation was voluntary and had nothing to do with their application for protection and residency or for their care treatment. It was also made clear that the young person had the final assent whether to accept the invitation or not, as well as the right to withdraw at any time. To facilitate processual consent (Raghallaigh and Sirriyeh, 2015), this information was repeated before the interview started and during the interview. The recruitment process yielded a group of 30 minors from different nationalities and their professional caregivers, all of whom were interviewed separately.

\section{Interviews about everyday life}

The empirical material consists of transcribed interviews with the young participants and their professional caregivers. At the time of the first interview the young persons 
had lived in Norway for approximately three to six months and were still at a care centre. One year later, once all had been resettled in new municipalities, new interviews were conducted with both the young person and his or her new professional caregiver. By this point, the young persons had been at the group homes for approximately seven to twelve months.

The interviews with the young participants were conducted in a separate room in the residencies by the first author, a clinical psychologist, and were structured as conversations about their everyday life. Informed by the life mode interview (Andenæs, 1991; Haavind, 1987), time was used as a structuring principle and the young participants were invited to talk about the events of the day prior to the interview, from waking up to going to bed. Through detailed and contextualised descriptions, the interviews focused on the affective, material and relational qualities of the events, and these events were used as points of departure to talk about associated retrospective and prospective events. Interpreters were used in the first round of interviews. The second time, most interviews were conducted without interpreters' help, although the young participants were invited to include them if needed.

As expected, the interviews from the second round were "thicker" and more nuanced than from the first round, possibly reflecting the young persons' functional silence and distrust (Kohli, 2006) when meeting the interviewer for the first time. Further, emphasising topics from their everyday life in the interview, seemed to act as a 
kind of shelter from other, generally contested topics of their lives, as for example the reasons for seeking asylum.

With the young participants' consent, their professional caregivers in both the care centre and later at the group home were interviewed in a similar way as the young ones, using time as the structuring principle in a conversation about the daily life of the particular young person. Of practical reasons, we used telephone interviews in every case. Also these interviews were audiotaped and transcribed verbatim. The interviews with the young participants and the professional caregivers are described in greater detail in a previous publication (Omland and Andenas, 2018).

\section{Analysing relational practices}

For the analysis, we selected only the complete interview cases consisting of interviews with both the young participant and the professional caregiver, before and after moving to new municipalities following the resettlement procedure, four interviews per case.

Given our interest in the development of relational practices in the context of residential care, not a family, we omitted two of the complete cases in which the young persons moved to foster care. This gave a total of 15 young participants, 4 girls and 11 boys, all between 13 and 16 years old at the time of the first interview. Their countries of origin were Afghanistan, Somalia, Angola, and Sri Lanka. 
The interviews with the young participants were read systematically in several steps, with the following analytical questions in mind:

1. With whom did the young persons create relationships during resettlement?

2. What characterized the relational practices performed within these

relationships in ways that seemed to facilitate a sense of togetherness for the young persons in their everyday lives?

These questions were applied to all interviews, first vertically to the interviews from each case, and then horizontally, across cases. The interviews with the young participants were given most attention. The interviews with the professional caregivers were mainly read as to give more context to the analytical questions described above, for example through giving detailed accounts of the way everyday life was organised at the care centres and group homes.

We were struck by the many and varied examples of how the co-habitant peers acted as resources for each other at the care centres. From the second step of the analysis and onwards, we therefore focused on relational practices among peers, and relational practices that seemed to facilitate a sense of togetherness, both at the care centres and the group homes. Surely, sense of togetherness did not imply harmonious relationships. Conflicts were experienced as well, including quarrels, teasing and at times, exclusion, but we did not find that conflicts between peers contradicted the presented relational practices. Still, when evaluating these results' potential for 
generalisation, it is important to bear in mind that grave conflicts and irreconcilability between peers at asylum centres have been reported by other researchers (e.g., Berg and Tronstad, 2015: 131). One central source of conflict relates to the different outcomes of the young people's applications for protection and residency and the associated challenges in creating a sense of togetherness in this situation (Berg and Tronstad, 2015: 132). Such narratives were not elicited in the present study, possibly reflecting that all the young participants were granted temporary residence permits and resettlement.

Memos were written for each of the steps described. The final memo categorised the different practices across cases, that we have named practices of (1) collective meaning-making, (2) emotional care, and (3) social inclusion.

As noted, the care centres and group homes differed significantly from each other in the abundance and variety of relational practices connected to a sense of togetherness, and we found no additional categories of the relational practices of interest at the group homes. Thus, for the reader to grasp the details and contexts of the three overarching practices, we first present them through how they seemed to unfold at the care centres and continue to discuss them through how the practices appeared at the group homes.

\section{The care centres: peer belonging and connectedness}


The care centres housed young persons of different nationalities and ethnicities. Four of the five care centres consisted of three to five care units, the last centre comprised of one care unit. Each unit housed six to ten young people. The staff typically organised everyday life by emphasising routines and shared activities for the cohabitants.

\section{Collective meaning-making practices}

The interviews with the young persons reflected the central human act of creating meaning (Bruner, 1990). The young persons were involved in creating such meaning together, and in different ways.

One practice was narrative work that connected their past, present and future contexts. Shared symbolic resources - shared language and shared meaning systems seemed to be basic requirements in order to transform past experiences to present narratives.

Some of the young participants, such as Tareq ${ }^{3}$ (aged 14), explicitly highlighted the significance of sharing references in such narrative work. He described how he and Masood, a fellow Pashtun peer at the care centre, drew upon their shared knowledge of home when mourning and longing for their families and the places they had left behind.

When I was sad or missed my family, he comforted me. When he was sad, I comforted him. [Sometimes] we bought an energy drink, and shared it. We talked about Afghanistan and listened to music. (...). There were no secrets. 
As the quote illustrates, the experience of collective meaning-making seemed to be central to Tareq's experience of being emotionally connected to Masood. Even a year after being separated far away from each other, owing to the resettlement procedure, Tareq described Masood as his best friend and as his brother.

The joint narrative work also illustrates a potential for collective post-trauma reconstruction, often localised in families (e.g., Kevers et al., 2017). Together, the young persons constructed narratives of the extraordinary and life-threatening events they had experienced, but not told to others. Tareq, introduced above, described how he empathetically asked the new Pashtun-speaking boys to tell their stories of their journeys to Norway. 'It makes me think of my own journey', he said. A potential that may be realised in such a setting when stories are related to one another, is the weaving together of individual recollections into collective narratives and transforming them into resourceful experiences, for example by drawing upon political or historical contexts (Rousseau, 2000). Studies regarding refugee families coping with trauma underline the significance of collective identifications in order for such resourceful transformations to happen (Rousseau, 2000).

The second collective meaning making practice was creating local versions of traditional practices. Family plays a fundamental role in creating continuity in cultural practices and patterns of relationships, and such connections may play a significant part 
in feeling 'settled' in exile (Ager and Strang, 2008: 178 ). Without access to their own families, the young people in the current study organised cultural and social practices in collaboration with other young people with similar cultural backgrounds, thereby creating continuity and a sense of familiarity in their lives. For example, similar religious background was used as a resource to continue praying practices. This was the case for Wahid (15) who was assisted by another Sunni boy at the care centre who introduced him to a web application that kept track of sunrise and sunset and the direction to Mecca.

Collaboration in traditional practices also enabled the young persons to mutually explore and experiment with shared traditions. An example was the use of traditional collective dance to explore innovative dance practices, as illustrated by Tareq, introduced above. In the interview, he used a film clip on his phone to demonstrate himself making solo dance moves with point of departure in a traditional group dance. He and his Pashtun friends were celebrating Eid, and Tareq explained that his solo dance was 'just for fun', demonstrating similar moves to those in popular music videos. The collective practice of dancing seemed to function as a field where they explored and tried out ways of making connections between the old and the new, between the 'here' and 'there', and between 'them' and 'us'. Such explorations might thus transform and transport traditional dance into dance practices that would potentially correspond with those at a local Norwegian nightclub and youth culture, and thus pointed to new 
belongings. For such a creative space to develop, the young persons needed to share some knowledge about the original forms to creatively modify them into new versions: new collective practices that suggested identities of multiple belonging (Ní Laoire et al., 2010).

The third collective meaning-making practice we termed understanding and distributing information about the residency and the asylum and resettlement process. The young persons helped each other to understand what to expect at the residency and from the staff, and how they should behave towards the latter. Qader (13) describes how a fellow Tadjik boy at the care centre helped him to understand the rules at the residency:

All the time he says: 'Are you all right?' Nice boy. He says 'Don't do this. Don't do this. Here it's not allowed to hit children', he says. Rules. He speaks Dari. He says to me: 'Do it like this'.

The fellow Tadjik boy took on the role of supervisor when Qader had newly arrived. The "supervisors" were more experienced and often shared the newcomer's native language. They knew something about their place of origin, as well as their potential concerns. This kind of supervision was further passed on, as the former "apprentices" supervised the next "generation" of newcomers. Most spoke about being supervised by peers in ways that seemed to be connected to an experience of being cared for, but there were exceptions from this. For example, when Qader moved from the care centre, he 
arrived in a group home with a fellow Sunni peer, and Qader seemed ambivalent to the direction this peer was paving an everyday life living for him:

He is praying a lot. He doesn't like to talk with... he doesn't like to be boyfriend with anybody, he's very Muslim (...). For example, he doesn't smoke - it's haram, he doesn't drink alcohol, and (...) when I play games, he turns to me and says 'Come let's pray'.

According to Qader, his class mates excitedly talked about the activities referred to in the quote - being romantically involved, smoking, drinking and playing games. As both the group home and the class at school were the primary places of interaction with peers in his everyday life, he was ambivalent towards this particular invitation.

\section{Practices of social inclusion}

The young persons helped each other in the process of creating or widening their social networks. The more experienced ones seemed to support the newly arrived and with whom they shared cultural background or interests, for example football. In this way, the more experienced ones seemed to try to "match" their peers based on shared features that they believed might enable them to develop friendships.

After being informed of their resettlement municipality, several of the young persons helped the moving girl or boy to getting to know other peers in their networks who lived nearby. This was primarily done by young people who shared cultural background, as exemplified by Qader's experience. He did not know anybody at the 
place where he was resettled, but a friend from the care centre knew a boy in a nearby city and informed this boy of Qader's move. According to Qader, the boy phoned him and said: 'Tomorrow, I will come to your place, and if you want, we can go to the mosque in [neighbouring city], and we can meet others there as well'. The invitation from his friend from the care centre thus widened Qader's social network even further.

\section{Practices of emotional care}

The practices already mentioned seemed to be central to the young persons' emotional well-being: their feelings of being cared for, committed to, understood and supported. However, some practices seemed to specifically target the regulation of young persons' emotions.

Some of the more experienced young persons helped those who were newly arrived (and often frightened), making them feel welcomed and cared for, such as by offering enjoyable activities like playing video games or watching amusing videos on YouTube. Some of these practices were initiated by the young persons, and other by the staff who encouraged the more experienced to take special responsibility for the newly arrived. Three girls from the same care centre all referred to this experience in their interviews. On their first days, other girls at the care centre helped them fold their clothes and put them in their closets. Awrala, a Somali girl aged 14 at arrival, additionally claimed that one of the girls living at the care centre, Maisara (from Central 
Asia), had arrived at the reception office to greet her with a staff member. The girl sat with Awrala on her first journey to the care centre, an event that most of the young participants described as frightening and bewildering. This girl seemed to achieve a special place in Awrala's narrative.

\footnotetext{
(So, who did you get to know in the beginning of your stay here?) Maisara. (Yes, that's the one who met you at the police office?) Yes. (Tell me a little about her, how did you get to know each other?) I came here and she welcomed me very nicely. She helped me to get my clothes in order in the closet. We had supper together (...). And she asked: 'Do you want to watch a movie?', and I said: 'Yes', and we watched a movie together.
}

Awrala seemed to have developed a sense of togetherness toward Maisara in the course of the two months they had lived together at the care centre. The experience of receiving care from a peer at a time of extraordinary uncertainty seemed to be a central aspect of this development.

The emotional care practice of bodily closeness was initiated by the young persons and seemed to calm down their peers, offering them a greater sense of security. Some claimed that they appreciated being near to each other at school when meeting new peers. Sleeping beside one another constituted a further example of this practice of bodily closeness. This widespread practice was particularly commonplace when the young persons experienced nightmares and anxieties at night. The staff typically did not allow for this to occur on weekdays lest young people disturb one another by joking and talking. Indeed, staff preferred that young persons knock on their bedroom door so that 
an adult could sit beside their bed. This rarely occurred, according to the staff.

Certainly, the young persons preferred being close to each other, and some told the interviewer that they sneaked into each other's rooms as quietly as possible. According to one care worker, the young persons preferred this kind of closeness in spite of not knowing each other particularly well or being especially good friends.

The young participants also reported that they encouraged each other, especially when detecting unrest. Stories of receiving such encouragement when feeling unhappy were narrated by the young participants as prominent episodes in what seemed to be the development of affectionate relationships. Drawing on shared symbolic resources such as a religious faith was often central:

I was sad because I was alone. (...). When I came and talked Pashto with [a fellow Pashtun peer], I felt better. And he said that there were other Pashtuns here. (...)[T] $]$ hey said "God is good" and "It will be better". (...). Now I feel very good. I am happy.

In this quote, Malem describes how fellow Pashtun peers encouraged him not to lose courage. These were peers with whom he had come to trust, but who would soon be moved to different parts of Norway and thus find themselves in a new place all alone again.

\section{The group homes: loneliness prevails}


During the process of resettlement, typically, relationships based on biological family were protected. Five of the participants arrived in Norway with a sibling and they were all resettled together. Some of the young persons who had family members living in Norway were resettled strategically, in geographical proximity to them, in order to facilitate visits. Similar strategies for maintaining friendships did not exist, however. With one exception, no considerations were made of the resourceful relationships that had already been established.

The group homes were comprised of young persons of different ages (often 14 to 18), and usually included four to six people, often of different cultural backgrounds. Two adults were always present at the group home, working in shifts (typically two days on, four days off), akin to the organisation of staff at the care centres.

No formal guidelines exist for how to compose the group of cohabitant young people. However, as suggested by some of the professionals, a strategy to avoid similarities in ethnic and cultural backgrounds seemed to exist. One professional referred to the experience that same-ethnic boys sharing household would facilitate an excessive mutual affiliation and loyalty, which would make it more difficult for the staff to take charge. And further, that the boys would exclude cohabitants of other ethnicities at the group home, creating "cliques", as well as lose their motivation to meet peers at school and in the neighbourhood. In particular, same-ethnic boys from Afghanistan were perceived as a poor match. 
Almost all of the young participants strongly objected to being separated from friends. In the second interview, several compared the relationships they had developed at the care centre with those at the group home: almost all missed the former and sought to maintain them. They tried to be close, now at a distance. Given that the young people were spread all over the country, this objective was mainly achieved via social media, especially Facebook, with weekly (and for several even daily) updates. The use of social media as a component of their social lives did unfortunately not receive elaborate attention in the interviews, and would be central to explore in future research.

The routines of everyday life at the group home were organised similarly to that at the care centre. But due to age variation, the cohabitants did not attend the same class, and few went to the same school. Furthermore, after-school activities were often organised as separate activities for each young person, rather than as joint activities as seen at the care centre. The care workers seemed to have as an ideal that the young people were to find 'their' special interests and join local peers.

'There's nothing for me here', stated Abdul when I spoke to him at the group home. One year earlier, when we met at the care centre, he had been very optimistic about his possibilities to make friends among the local boys after moving as part of the resettlement procedure. However, this did not happen. According to Abdul's primary care worker at the group home, local young people had shown little interest in getting to know him - a common experience for many - and he had not made friends at the group 
home either. Given that nobody at the group home shared Abdul's religion, he was alone when cooking and eating food after dusk during the month of Ramadan.

Therefore, he greatly appreciated when his long-distance friend from the care centre visited him and they could do this together. But on the other days of Ramadan, nobody was available to share what should be central social events for Abdul.

There were exceptions form the striking overall picture of loneliness, and the three overarching resourceful relational practices from the care centre could also be identified in the group homes. Developing and distributing knowledge about the local community represented the most typical collective meaning-making practice, and the young persons were engaged in widening each other's social networks. However, the relational practices were less varied and abundant than in the care centres.

In particular, there were few descriptions of emotional care practices at the group homes. There were examples of welcoming practices and encouragement, but the interviews conveyed none of the more intimate regulations of emotion, such as bodily closeness. While sleeping beside each other was a prevalent practice at the care centre, no such examples were described in the interviews at the group homes, aside from those very few who had been resettled together. The young persons who complained about nightmares and who were often afraid to sleep at night tried to cope individually in order to distract themselves and calm down, such as by sleeping with the light on, chatting with friends on the Internet, watching a movie or listening to music. A shift 
appeared to occur from a collective coping strategy, as seen at the care centres, to more individual coping strategies.

\section{Different institutions - different sociomaterial conditions for conducting everyday life}

The separation of friends as part of the resettlement procedure, was acknowledged by the professionals as emotionally difficult for the young ones, but as something they just had to live through. Staff at the care centres seemed to expect they form new affectionate relationships relatively swiftly after moving, as they had already shown such a capacity. Yet, in the second interview at the group homes, this was not the story told. Moreover, the same young persons described by staff at the care centres as social and extroverted could be characterized by staff at the group homes as introverted and lacking social skills. The longitudinal design of this study enabled us to spot these incongruences. In addition, the longitudinal design enabled us to turn our attention to how the care centres and the group homes could represent different sociomaterial conditions for the evolvement of friendships. A third and final analytic step was thus added: How were the three overarching relational practices grounded in everyday life at the care centres and at the group homes, respectively?

This final step involved reviewing each case and identifying the ways in which the three overarching practices were grounded in the two different contexts of everyday 
life (before and after moving from the care centre to the group home as part of the resettlement procedure). We explored the ways in which the residential care institutions were composed and arranged materially, socially and spatially, and how that might be of significance for the conduct of the three overarching relational practice in everyday life. This step resulted in memos for each case at the care centre and at the group home, and memos describing the two contexts across cases. Finally, we compared the final two memos to shed light on the importance of everyday life contexts for the evolvement of the three relational practices.

Although the care centres as well as the group homes were residential care arrangements, the shift from waiting for resettlement to being resettled seemed to pose different arrangements of everyday life at the institutions.

\section{Care centres: A collective conduct of everyday life}

First, at the care centre the young persons shared everyday life across context. They moved together throughout the day, not only at the care centre itself but also in the classroom and in sports and leisure activities. And they moved together between places by walking or taking the school bus together. This joint movement from one place to another was used as a space for joint meaning-making, where they could draw upon their shared routines, and shared references to places and persons. Typically, at the care centre the young persons described themselves as 'we': as a unit that moved together 
through the day. This was the case for the young persons across cultural backgrounds. The staff seemed to build upon this notion of a 'we', organising shared activities for all of the children throughout the day. The children hence became each other's constant witnesses and companions.

Second, the care centres were composed of groups of young persons who shared cultural backgrounds. In part, this represented an implication of housing a larger group of children, but it also comprised a strategy utilised by staff to help boys and girls with shared cultural backgrounds to meet in and across care units. Accordingly, the young persons could make use of mutual meaning systems and traditional practices in everyday life, and in the process find a sense of continuity, safety and belonging.

\section{Group homes: an individual conduct of everyday life}

As noted, the group homes housed fewer children than the care centres. They were located far away from each other, rendering it difficult for young people to meet other unaccompanied peers across residencies on a daily, or even weekly, basis. In addition, the group homes consisted of children of different ages, reducing the possibility of a collective conduct of everyday life, as was prominent at the care centres.

Aadel's (13) description of his everyday life at the group home illustrates the sparse availability of relational resources in his everyday life. Aadel was resettled in a group home with three other boys, aged 16, 17 and 18. Two of the boys were from 
Afghanistan and the third was from Somalia, like Aadel. Aadel spoke yearningly of his previous relationships with the cohabitant boys at the care centre. He emphasised how they did "everything" together, highlighting the collective conduct of everyday life at the care centre, in contrast to his descriptions of everyday life at the group home, which was more like an individual trajectory through the day. He referred to a particular day, when he had some additional school-related obligations. Loneliness was conspicuous throughout the story:

I came home from school. Nobody was home, just the staff, but I was very tired. Because yesterday, we had a party at school. And I made sambosa - it's a dish from Somalia. At 5.30 a.m. I woke up to make sambosa, and when I finished I went back to bed to sleep. I got up at 7.45 and brushed my teeth, ate breakfast, and then [the staff] drove me to school. We ate together with the pupils, and when we finished I got home and I was so tired and had a headache. I went to sleep.

Given that Aadel was not the same age and accordingly not in the same class at school as the other cohabitants at the group home, he had to prepare for the party at school by himself, and present himself and his cultural heritage on his own. Moreover, when he arrived home, he had nobody with whom to discuss the event. The conditions did not enable him to cope collectively with cohabitant peers, as shared experiences and references from the past or from the present were almost non-existent.

The relational practices that were reinforced by the staff at the care centres did not seem to be encouraged in the same way at the group homes. The separation of friends, the avoidance of similarity in cultural backgrounds at some of the group homes, 
and the organisation of everyday life based on individual trajectories, made it difficult to develop relational practices that facilitated a sense of togetherness.

\section{Discussion and concluding remarks}

In order to promote the health and development of unaccompanied refugee minors, understanding how they create and take part in relational practices that facilitate sense of togetherness in everyday life is crucial. This was a starting point for our study, and in the presentation of the results, we have elucidated not only the details of such relational practices, but also under what circumstances they may evolve. The young people in the study acted as resources for one another through creating a sense of continuity and personal belonging in their new country of residence in several ways. Their creative collective acts had potentials for restoring a sense of continuity and directionality through collective reorientations in the midst of multiple transitions. Considering our understanding of these young people's past, present and future contexts, characterised by losses, loneliness and uncertainty, creating and securing continuity in their lives is especially important.

As such, the results underline that there is more to these relational practices than enjoying each other's company. It has do with health and well-being, and can be seen as the young persons' own health-care work (Mayall, 1998). Research on care practices in 
families underline that sharing routines in everyday life is a central condition in order to become important persons to each other (Haavind, 1987) and depicts health-care work as collaborative enterprises between mothers and children - those who share the routines of everyday life (Mayall, 1998). This study elucidate similar phenomena, but with peer groups as central collaborative units.

The results also suggest the relational practices' dependence on sociomaterial conditions of everyday life. Sharing everyday life across contexts as well as sharing interpretative tools such as language, meaning systems and social practices facilitated shared references and were thus vital for collective coping practices. However, according to our analysis, several of the young persons were resettled with cohabitant peers who did not share interpretative resources. Thus, the resettlement practices in several cases weakened the conditions for collective coping to evolve. The resettlement policies, by its separation of friends and moving each young person separately to completely new locations, not only weakened the young persons' possibilities to develop health-promoting strategies, but also added to their hardship. Accordingly, reconsidering these policies should be included in strategies to promote the health for the young persons.

The practical implications of this study may be summed up as three reminders. First, be aware of the geographical placement of young people, in order to ensure the possibility of being near to friends with whom they share significant contexts of 
everyday life, such as school, and also be resettled together (akin to siblings) based on the relational qualities of the relationships developed at the care centres. Second, be aware of the composition of cohabitants at the group home, by ensuring possibilities for collective meaning-making based on shared symbolic resources and social practices. Third, be aware of the day-to-day organisation of everyday life, by ensuring the conduct of everyday life as a collective process, as well as assisting relational practices among peers.

The knowledge that has been highlighted in this article regarding the significance of relational practices among unaccompanied refugee minors has relevance beyond this particular group. The study has given new insight into how acts of care and support that are usually associated with vertical care relations can be performed even in horizontal relations, by peers, and thus make visible relationships that hold resources for young persons' development and mental health.

\section{Acknowledgments}

We are grateful to all the participants in this research project for sharing their experiences. We would also like to thank Professor Tine K Jensen, Associate Professor Mogens Jensen, Professor Jaan Valsiner and Professor Nora Sveaass for contributing with ideas and comments throughout the research process. A special thanks to Professor 
Ravi Kohli and two anonymous reviewers for providing valuable comments on the manuscript.

\section{Notes}

${ }^{1}$ In Norway, the care for unaccompanied asylum-seeking minors below 15 years at arrival is delegated to the Child Welfare Services and secured under the Child Welfare Act, while the care for those over 15 is delegated to the Directorate of Immigration with significantly lower care standards. This differential treatment has been repeatedly criticized by the UN Committee on the Rights of the Child (e.g. UNCRC, 2018).

${ }^{2} \mathrm{~A}$ temporary residence permit usually allows for applying for a permanent residence permit after three years of residency in Norway, but with no guarantee. If new information is obtained that changes the grounds on which the application was assessed, or if convicted of a crime, his/her application for a residence permit can be rejected.

${ }^{3}$ All names are pseudonyms 


\section{References}

Ager A and Strang A (2008) Understanding integration: A conceptual framework. Journal of Refugee Studies 21(2): 166-191. doi:10.1093/jrs/fen016

Andenæs A (1991) Fra unders økelseobjekt til medforsker? Livsformsintervju med 4-5-åringer [From research object to co-researcher? Life mode interviews with 4-5 year olds]. Nordisk psykologi 43(4): 274-292.

Berg B and Tronstad KR (2015) Levekår for barn i asylsфkerfasen [Living conditions for children applying for asylum] Report, 8275704057 Trondheim: NTNU Samfunnsforskning.

Bruner JS (1990) Acts of meaning. Cambridge, Massachusetts: Harvard University Press.

Cohen S (1992) Stress, social support, and disorder. In: Veiel HOF and Baumann U (eds) The meaning and measurement of social support. New York: Hemisphere Press, 109-124.

Dreier O (2016) Conduct of everyday life. In: Schraube E and Højholt C (eds) Psychology and the conduct of everyday life. London: Routledge, 15-33.

Haavind H (1987) Liten og stor: Mфdres omsorg og barns utviklingsmuligheter [The little one and the big one: Maternal care and the developmental possibilities for children]. Oslo: Universitetsforlaget.

Hagerty BMK, Lynch-Sauer J, Patusky KL, et al. (1992) Sense of belonging: A vital mental health concept. Archives of Psychiatric Nursing 6(3): 172-177. doi:10.1016/08839417(92)90028-H

Jensen TK, Fjermestad KW, Granly L, et al. (2015) Stressful life experiences and mental health problems among unaccompanied asylum-seeking children. Clinical child psychology and psychiatry 20(1): 106-116. doi:https://doi.org/10.1177/1359104513499356

Kevers R, Rober P and De Haene L (2017) The role of collective identifications in family processes of post-trauma reconstruction: An exploratory study of Kurdish refugee families and their diasporic community. Kurdish Studies 5(2): 107-133.

Kohli RKS (2006) The sound of silence: Listening to what unaccompanied asylum-seeking children say and do not say. British Journal of Social Work 36(5): 707-721. doi:10.1093/bjsw/bch305

Lefebvre H (1991) Critique of everyday life: Foundations for a sociology of the everyday. London: Verso.

Mayall B (1998) Towards a Sociology of Child Health. Sociology of Health \& Illness 20(3): 269-288. doi:10.1111/1467-9566.00102

McMillan DW and Chavis DM (1986) Sense of community: A definition and theory. Journal of Community Psychology 14(1): 6-23. doi:10.1002/1520-6629

Morgan DHJ (2011) Rethinking Family Practices. Basingstoke: Palgrave Macmillan.

Ní Laoire C, Carpena-Méndez F, Tyrrell N, et al. (2010) Introduction: Childhood and migration - mobilities, homes and belongings. Childhood 17(2): 155-162. doi:https://doi.org/10.1177/0907568210365463

Ní Raghallaigh M (2011) Relationships with family, friends and God: The experiences of unaccompanied minors living in Ireland. In: Darmody M, Tyrrell N and Song S (eds) The changing faces of Ireland: Exploring the lives of immigrant and ethnic minority children. Rotterdam: Sense Publishers, 
Omland GB and Andenas A (2018) Negotiating developmental projects: Unaccompanied Afghan refugee boys in Norway. Childhood 25(1): 78-92. doi:10.1177/0907568217718032

Oppedal B and Idsoe T (2015) The role of social support in the acculturation and mental health of unaccompanied minor asylum seekers. Scandinavian Journal of Psychology 56(2): 203-211. doi:https://doi.org/10.1111/sjop.12194

Oppedal B, Seglem K and Jensen L (2009) Avhengig og selvstendig. Enslige mindreårige flyktningers stemme i tall og tale [Dependent and independent: Unaccompanied refugee minors' voices through numbers and words] Report, Oslo: Norwegian Institute of Public Health.

Raghallaigh MN and Sirriyeh A (2015) The negotiation of culture in foster care placements for separated refugee and asylum seeking young people in Ireland and England. Childhood 22(2): 263-277.

Rogoff B (2003) The Cultural Nature of Human Development. Oxford: Oxford University Press.

Rousseau C (2000) Les réfugiés à notre porte: Violence organisée et souffrance sociale. Criminologie 33(1): 185-201. doi:10.7202/004743ar

Schraube E and Højholt C (2016) Introduction. In: Schraube E and Højholt C (eds) Psychology and the Conduct of Everyday Life. London: Routledge, 1-14.

Sourander A (1998) Behavior Problems and Traumatic Events of Unaccompanied Refugee Minors. Child Abuse \& Neglect 22(7): 719-727. doi:https://doi.org/10.1016/S01452134(98)00053-2

Stretmo L (2014) Governing the unaccompanied child: Media, policy and practice, $\mathrm{PhD}$ Thesis, University of Gothenburg, Sweden.

Tanggaard L (2013) The sociomateriality of creativity in everyday life. Culture \& Psychology 19(1): 20-32. doi:10.1177/1354067x12464987

UNCRC (2018) Concluding observations on the combined fifth and sixth periodic reports of Norway Report, Geneva: OHCHR. Available at: https://tbinternet.ohchr.org/_layouts/treatybodyexternal/Download.aspx?symbolno=C $\mathrm{RC} \% 2 \mathrm{fC} \% 2 \mathrm{fNOR} \% 2 \mathrm{fCO} \% 2 \mathrm{f5}-6 \& \mathrm{Lang}=\mathrm{en}$

Valsiner J (2000) Culture and Human Development: An Introduction. London: Sage Publications.

Yuval-Davis N (2006) Belonging and the politics of belonging. Patterns of Prejudice 40(3): 197-214. doi:10.1080/00313220600769331 